\title{
Article
}

\section{Developing anti-counterfeiting measures: the role of smart packaging}

Soon, Jan Mei and Manning, Louise

Available at http://clok.uclan.ac.uk/28349/

Soon, Jan Mei ORCID: 0000-0003-0488-1434 and Manning, Louise (2019) Developing anti-counterfeiting measures: the role of smart packaging. Food Research International, 123 . pp. 135-143. ISSN 0963-9969

It is advisable to refer to the publisher's version if you intend to cite from the work. http://dx.doi.org/10.1016/j.foodres.2019.04.049

For more information about UCLan's research in this area go to http://www.uclan.ac.uk/researchgroups/ and search for < name of research Group>.

For information about Research generally at UCLan please go to http://www.uclan.ac.uk/research/

All outputs in CLoK are protected by Intellectual Property Rights law, including Copyright law. Copyright, IPR and Moral Rights for the works on this site are retained by the individual authors and/or other copyright owners. Terms and conditions for use of this material are defined in the policies page.

\section{CLoK}

Central Lancashire online Knowledge www.clok.uclan.ac.uk 
Abstract

Counterfeiting of food and beverage products is rife and premium brands are often targeted by fraudsters. Such is the case with Scotch whisky, a global, reputable brand revered for its heritage and tradition. Using Scotch whisky as a case study, the aim of this paper is to review existing literature and industry information to determine the market and personal consequences of counterfeiting activities and consider the packaging related anti-counterfeiting measures that can be employed within a wider anti-counterfeiting strategy. A typology of counterfeiting activities is developed including: teardown counterfeiting, product overruns, malicious activities and document counterfeiting. Anticounterfeiting measures are used to deter, detect and control counterfeiting activities and different packaging related approaches include the use of smart covert and overt technology. Most smart packaging-related anti-counterfeit technologies are stand-alone systems and this presents a vulnerability. An integrated anti-counterfeiting measures strategy, employed by business, the supply chain and the government is required to reduce the risk of the sale of counterfeit food and beverage products.

Keywords: counterfeit; fraud; packaging; smart technology, Scotch whisky

\section{Highlights:}

- Counterfeiting is a major concern in the food and beverage industry.

- Branded products are at risk of counterfeiting.

- Smart packaging solutions reduce the risk of counterfeiting.

- Packaging related anti-counterfeiting measures are essential for crime reduction.

\section{Introduction}

Counterfeiting activities are ubiquitous in industry affecting products from pharmaceuticals and medical equipment through to machine, electrical, automotive and aircraft parts, clothing, fashion items, movies, computer software and cigarettes (Berman, 2008). The Global Brand Counterfeiting Report (2018) estimates that the value of global counterfeiting is $\$ 1.2$ trillion per annum and will reach 
$\$ 1.82$ trillion by 2020 with online distribution of counterfeit products being in the region of $\$ 323$ billion annually. Counterfeiting of food and beverage is an age-old problem. Examples go back to ancient times. A stopper for a wine amphora dated $27 \mathrm{BC}$ shows an attempt to replace Roman wine with cheaper French wine and in the $14^{\text {th }}$ century the Elector Palatine in the Holy Roman Empire sentenced a wine retailer to death for attempting to sell counterfeit product (Phillips, 2007). Recognized examples of counterfeit food and beverage products include wine, baby formula milk (Berman, 2008); and alcohol (Kuballa et al., 2018). Ten percent of bottles or cans of beer sold in the United Kingdom (UK) is said to be counterfeit (Snowdon, 2012). Trading counterfeit alcohol is opportunistic and there are links between the sale and production of counterfeit alcohol and Eastern European criminal groups based in the UK, the products e.g. vodka are often being sold through small retailers or private networks (FCASA, 2016). Examples of UK seizures of counterfeit alcohol show the types of problems identified (Table 1).

\section{Take in Table 1}

Smuggling is not considered in depth in this paper, but there is widespread evidence of smuggling of counterfeit goods (Soon \& Manning, 2018). Counterfeiting activities include the sale and manufacture of products using a trademark without the brand owner's permission (Yoo \& Lee, 2005). Counterfeiting activities are economically motivated often substituting an inferior product that is inexpensive relative to the cost of production of the genuine article (Bodner, 2014). Counterfeiting is associated with goods that possess high brand value (Wilcox, Kim \& Sen, 2009). The practice leads to tangible losses such as reduced sales and sales revenue, reduced profit, loss of development costs, employment, income and sales tax revenue and increased legal fees, trade deficit, verification and detection costs (Gentry, Putrevu \& Shultz, 2006; Berman, 2008; Phau, Sequeira \& Dix, 2009; Kaufmann, Petrovici, Gonçalves Filho \& Ayres, 2016; Ting, Goh \& Isa, 2016). Ultimately, counterfeiting undermines brand value, goodwill, consumer confidence, brand reputation and associated intellectual property rights and trademarks and, if the counterfeit goods are sub-standard and it is difficult for consumers to differentiate them from the legitimate product, can lead to liability claims (Yao, 2005; Bian \& Moutinho, 2009; Staake, Thiesse \& Fleisch, 2012; Bodner, 2014). The Trade-Related Aspects of Intellectual Property Rights (TRIPS) Agreement defines counterfeit trademark goods as: 
"any goods, including packaging, bearing without authorisation a trademark that is identical to the trademark validly registered in respect of such goods or that cannot be distinguished in its essential aspects from such a trademark, which thereby infringes the rights of the owner of the trademark in question under the law of the country of importation" (WTO, 1994, Article 51).

Emotional brand attachment will reduce the likelihood that consumers will willingly purchase an alternative counterfeit product (Kaufmann, Petrovici, Gonçalves Filho \& Ayres, 2016). However, there is a tipping point where the purchase of counterfeit products may be seen as acceptable, and this challenge is considered here using whisky as an example product.

Scotch whisky represents around one quarter of the UK's total food and beverages exports to 200 global markets and supports 40,000 jobs and is worth an estimated $£ 4$ billion in annual exports (Scotch Whisky Association, n.d.; Shand et al., 2017). Scotch whisky is a luxury food item making it a target for counterfeiters to produce illicit alcohol under its protected name (Stupak, Goodall, Tomaniova, Pulkrabova \& Hajslova, 2018). Scotch whisky is made in Scotland from three raw materials: cereals, yeast and water and this process is currently set out in the Scotch Whisky Regulations (2009). Malt whiskies are made from malted barley (Stupak, Goodall, Tomaniova, Pulkrabova \& Hajslova, 2018). However, it is the process by which Scotch whisky is made that is defined and not the analytical properties of the finished product (Aylott \& MacKenzie, 2010; Scotch Whisky Regulations, 2009).

In 2015-2016, seizures of "fake" famous alcohol brands (including whisky and vodka) were made in Greece. Genuine empty bottles were smuggled from Bulgaria and the counterfeits were produced in underground laboratories (Interpol-Europol, 2016). Meanwhile, in another incident in Zambia, stolen branded whisky was sold to illicit alcohol producers. Inspections and closure of other underground factories was carried out in Operation Opson VII (Interpol, 2018). In another case, more than 1.6 million litres of illegally produced alcohol was seized in Russia. Indeed, recent tests revealed that more than a third of vintage Scotch whiskies could be counterfeit at a value of $£ 41$ million (BBC, 2018). Whisky is produced in other parts of the world but different ingredients are often used. US whiskey is made in Kentucky, Tennessee and other locations from a range of cereals including rye, corn, barley and wheat and differing maturation processes (Aylott \& MacKenzie, 2010). Jack Daniel's Tennessee Whiskey is the largest volume selling US whiskey with $10 \%$ of market share and annual sales of $\$ 233$ 
million dollars (Statista, 2019). The length of time that the whiskey is stored will vary by production method and in order to give a "peaty" quality to some Scotch whiskies, damp malted barley is subjected to peat smoke giving it a unique taste.

In 2011, a gang of men were found guilty of producing illegal vodka in the UK, with one man receiving a suspended sentence, one received an eighteen month prison sentence and two more sentences of seven years (BBC, 2011), being the maximum jail sentence for fraudulent evasion of duty as laid down by the UK Customs and Excise Management Act 1979. The financial penalty on summary conviction is $£ 20,000$ or three times the value of the goods whichever is the greater. The aim of this research has been to consider the types of counterfeiting that can occur in the food and beverage supply chain and the approaches to developing effective anti-counterfeiting strategies, including the use of smart packaging related technologies. The lens through which counterfeiting is considered here is Scotch whisky. It is not the aim of this research to review the analytical techniques (e.g. chemical, biomolecular, spectroscopic or isotopic) used to detect counterfeit whisky as this has been reviewed elsewhere (Kamiloglu, 2019; Urickova \& Sadecka, 2015), and the focus is on the use of smart technologies to reduce the risk of counterfeiting. This paper introduces the concept of counterfeiting and then considers the types of counterfeiting activities and potential anti-counterfeiting strategies and measures that can be used in order to provide recommendations for the use of smart technologies as part of a wider business strategy.

\section{Typology of counterfeiting}

Counterfeiting involves either substitution, the placing of inferior products in authentic or reused packaging; duplication, the direct copying of packaging, products, and/or instructions; tampering through interfering with packages or labels and replacing the real product with spiked, pilfered, or stolen goods; and returns and warranty fraud (Zadbuke, Shahi, Gulecha, Padalkar \& Thube, 2013).

When critiquing the typology of counterfeiting it is important to consider the innate nature of branded goods i.e. those goods or products that bear a registered trademark with associated intellectual property rights and how these can be copied by others. Whereas a counterfeit is an exact copy of the original food item, "imitation, knock-off or copycat goods" look similar to the branded goods but are not identical and often lack the same level of quality or performance (Le Roux, Bobrie \& Thébault, 
2016; Wimmer \& Yoon, 2017). Imitations or copy-cat products do not bear a counterfeit copy of the

trade-mark. Shanzhai imitation represents a type of imitation that mimics the original brand through surface or functional similarities, but often provides enhanced or innovative features adapted to local market needs (Qin, Shi, Song, Stöttinger \& Tan, p2292018) i.e. they build in enhancements or features that the original product does not include, thus it is not a direct copy.

Whilst counterfeiting is illegal, in some cases imitation, although unauthorized by the brand owner, may be legitimate and not infringe any copyright legislation. This activity, as seen with private label imitation of branded products is undertaken to make products "look like" the original. Kapferer (1995) describes this imitation as a "halo of resemblance" for consumers who can make inference from the similarity of the visuals and context of the branded product. Similarity with the original brand can confuse consumers and can fall into two types: firstly litera/ where a product name can have common letters or a similar sequence of letters and semantic meaning i.e. the name is different but the extrinsic attributes of the product are imitated (Van Horen \& Pieters 2012; Le Roux, Bobrie \& Thébault, 2016). However product imitation may lead consumers to believe there is a link or affiliation between the imitation product and the imitated brand (Zaichkowsky, 2006). This confusion can lead to a reduction in brand preference and a consumer trend towards buying the lower price alternative (Aribarg, Arora, Henderson \& Kim, 2014). With imitation products, there is no intention to deceive the consumer, but there is an implicit, if not explicit, driver to use similarity to drive sales of the imitation version.

\subsection{Non-deceptive counterfeit goods}

Non-deceptive counterfeiting can only exist if there is demand from consumers for the items as well as the supply from fraudsters (Cesareo \& Stöttinger, 2015). Le Roux, Bobrie \& Thébault (2016) differentiate between deceptive and non-deceptive counterfeiting the former where the consumer is unaware that the product is counterfeit and the latter where the consumer purchases the product knowing that it is counterfeit. Non-deceptive counterfeit goods are distinguishable either visually or by the type of sales and distribution channels through which it is sold from the branded products they are designed to represent (Grossman \& Shapiro, 1988; Berman, 2008; Yao, 2015; Wu, Gong \& Chiu, 2016). Consumers may willingly choose to buy non-deceptive counterfeit goods as they see them as a bargain (Thaichon \& Quach, 2016). It is difficult here with the terminology in the literature to clearly differentiate 
between what the sources state as being an imitation product or what are indeed non-deceptive counterfeit goods. In this paper, imitation is an alternative clearly distinct "look-alike" rather than a "direct-copy" but still distinguishable product.

\section{2 "Tear-down" counterfeiting}

Tear-down goods are designed in a process of exact duplication to deceive the unsuspecting consumer (Berman, 2008). This means that the product is reverse engineered by breaking down the genuine product layer by layer to determine how the product can be rebuilt to appear to be the branded product. This approach may involve analysis and testing of the product itself or the theft of specifications, blueprints or other intellectual property.

\section{3 "Third shift" or product overruns}

Product overruns occur when an outsourced manufacturing supplier continues production after termination of the contract, or outside the hours or volumes agreed for manufacture, the so-called "third-shift" (Berman, 2008; Wimmer \& Yoon, 2017). The additional production may be covered up by false declarations of production wastage or instances of non-conforming material. These products are difficult to distinguish from legitimate product especially where authentic ingredients or packaging have been used (Berman, 2008). A further form of counterfeit goods are seconds or rejects that are not destroyed as the brand owner requested but are instead sold on by the outsourcer as "first-quality" in grey, illicit channels of distribution (Fogel, 1986; Berman, 2008 Cesareo, 2016).

\subsection{Malicious counterfeiting}

Malicious counterfeits are designed to appear to perform correctly, but then malfunction at critical times or open security breaches so that adversaries gain advantage (Bodner, 2014:427). Malicious counterfeiting can also be a problem with digital systems that can lead to intentional hardware failure (Takahashi, Nagata, \& Miura, 2018). Fake hardware can make organizations vulnerable to cybersecurity risks and the introduction of malware at a later date. Therefore, it is essential that there are effective mitigation strategies in place.

\subsection{Document and packaging counterfeiting}


Counterfeit documents are documents that are reproductions of the original valid document (Vieira, Silva, Antunes \& Assis, 2016). It is important for organizations to consider how they will ensure the integrity of documentation they use or receive. Anti-counterfeiting elements in documents or packaging include: watermarks, fluorescent fibres and planchettes, guilloche patterns, fluorescent and magnetic inks, optically variable inks, rainbow printing, microprinting, latent images, scrambled indicia, laser printing, photos, signatures, embossing stamps, optically variable devices, protective films, perforations, machine readable security, and retro-reflective patterns" (Vieira, Silva, Antunes \& Assis, p4232016). Planchettes are small flat components (1-5mm) added to paper during the production process that carry visible or invisible security features such as ink, microprinted text or symbols, chemically reactive substances or thermochromatic inks that change color under different temperatures (Nanomatrixsecure, nd). A guilloche pattern is a decorative interlaced pattern that is embedded within official documents and bank notes. Scrambled indicia are formed though a patented process that uses a scrambled image or stamp to encode text or graphics within the design so it is unreadable without specific equipment.

\subsection{Summary}

A typology of imitators and counterfeiters has been drawn together from the literature (Table 2). The table uses factors such as capabilities, business model, strategic focus, and functionality and potential countermeasures to mitigate the risk of counterfeiting. These countermeasures focus in part on supplier and procurement management procedures. There are multiple socio-economic factors that frame counterfeiting activities (Table 3). Increased systems complexity and globalization of supply chains, greater outsourcing of design and manufacture, and weak governance and surveillance of intellectual property rights across national boundaries between one legal jurisdiction and another increase the risk of counterfeiting (Bodner, 2014). All these factors need to be taken into consideration when developing anti-counterfeiting measures.

Take in Tables 2 and 3

Anti-counterfeiting technologies are used to deter, detect and control counterfeiting. They should allow customers and/or individual consumers to examine the product and verify that the product is not a counterfeit. However the anti-counterfeit features used on packaging must be difficult to replicate 
(Hopkins, Kontnik \& Turnage, 2003). The range of anti-counterfeiting measures including smart packaging technologies are now considered.

\section{Anti-counterfeiting measures}

Brand owners need to address the risk of counterfeiting and develop systems to track, trace, detect and take action on what they believe to be counterfeit products (Ting, Goh \& Isa, 2016). Two elements of traceability are of interest as anti-counterfeiting measures: logistics traceability and qualitative traceability (Folinas, Manikas \& Manos, 2006; Ringsberg, 2014). Logistics traceability has three elements tracking, tracing and logging. Tracking is forward traceability from ingredient to finished product; tracing is reverse traceability from finished product to ingredient and logging is the details of the physical movement of the product e.g. quantity, origin, destination, dispatch date. Qualitative traceability links additional information to the product e.g. pre-harvest and post-harvest techniques, storage and distribution conditions. It is this information that underpins the brand value of the product.

Secondly, brand owners need to provide information to consumers to increase awareness of the risk of counterfeit product especially through the role of Government and/or celebrity endorsed information campaigns (Ting, Goh \& Isa, 2016). These Government driven media campaigns should promote ethical purchasing and usage standards especially the safety implications of counterfeit goods and the impact on legitimate business of such behavior (Thaichon \& Quach, 2016). Regulatory controls for reducing on-line sales of counterfeit products should set standards and strengthen the penalties for sellers and buyers deviating from legitimate practice and also strengthen enforcement activities (Thaichon \& Quach, 2016). Berman (2008) suggests that to detect and reduce counterfeiting activity, protocols need to be put in place that encompass four steps:

(1) develop early warning signals of counterfeiting activity. These include: a sudden decrease in sales or increased grey market activity e.g. a large volume of product being sold in discounters, estores or internet sites, or an increase in product failure rates, returns and claims especially if those products are difficult to trace to legitimate production records;

(2) invest in management systems to monitor, deter, and remove counterfeit products and mitigate wider counterfeiting activity. These costs include the hiring of internal investigators or private investigators or setting up false companies to purchase the potentially counterfeit products. Investing 
in communication strategies with consumers about the danger of purchasing counterfeit products is also crucial so they are aware of the problems that can occur.

(3) using demand-side strategies to deter counterfeiting activities in the first place. These include: taking legal action where required, improving control of outsourced suppliers and building trust based relationships and implementing verification activities. Another strategy is to outsource parts production only and then to assemble the finished product within the brand owner's own business so potential counterfeiters cannot use "third-shift" techniques. Embedding track and trace and/or authentication smart and databased technologies will also deter counterfeiting; and

(4) using supply-side strategies to deter counterfeiting organisations e.g. the use of software to monitor websites that use key terms associated with the branded products especially those terms subject to intellectual property rights and restrictions.

Another element of these protocols is anti-counterfeiting hurdles. Hurdles are the formal system components that reduce opportunity for counterfeiting by either as a deterrent or by assisting in detection of activity (Spink et al. 2015; Soon, Manning, \& Smith, 2019). Hurdles can be physica/ in terms of protecting structural assets (barriers, enclosed production systems), or artefact-based such as procedures and protocols or cyber-protection via firewalls and virus software (Manning, 2019). Anticounterfeiting measures are therefore hurdles developed as online or off- line measures that are intended to dissuade consumers from buying counterfeit products and instead designed to encourage them to become advocates against fakes and imitations (Cesareo \& Stöttinger, 2015). Anticounterfeiting measures identified in the literature have been categorized according to their mode of operation: communication related, management related, distribution related, product related, process related, and social value related (Table 4).

The rise of the use of the Internet, with limited governance around anti-counterfeiting measures, has allowed a global distribution channel to develop for counterfeit goods to billions of people (Berman, 2008; Cesareo \& Stöttinger, 2015). Counterfeit operations can set up multiple websites that are visually similar to the authentic web presence often hiding behind the anonymity of the international 
scope of operation and the limited hurdles that are in place to prevent their activities (Yao, 2015). Some counterfeiters in the physical world too set up front companies or front personnel to register businesses and pass money through third parties and also forge production, sales and stock records, and use real food product names so forensic accounting may be limited in how it identifies evidence of counterfeiting (Berman, 2008). However, there is an increasing emphasis on the use of smart technologies embedded into packaging that can reduce the risk of counterfeiting. The role of packaging related anticounterfeiting measures is now considered in more detail, with a focus on their application in the Scotch whisky industry.

\section{Packaging related anti-counterfeiting measures}

\subsection{Control of used packaging}

According to SafeProof (2018), refilling and reusing spirit alcohol and wine bottles is one of the most common counterfeiting practices. Selling empty and labelled alcohol and wine bottles drives a return (Tobiassen, 2014) and so trading empty bottles is undertaken and for excellent wines the bottles may be resold for as much as $£ 300$, so producers request that the empty bottles are destroyed at the table at restaurants (Lecat, Brouard \& Chapuis, 2016). Refilling empty bottles is the preferred method among counterfeiters (Przyswa, 2014a) especially in China (Lavin, 2013), indeed a network for the recovery of empty bottles were set up by Chinese counterfeiters. Counterfeiters are also able to purchase online replicas of bottles, caps, labels and boxes to allow them to produce counterfeit product with lower grade alcohol (SafeProof, 2017).

\subsection{Traceability anti-counterfeiting measures (Track and Trace Technologies)}

A barcode is an optical machine-readable symbol consisting of a pattern of bars and spaces to represent the product and the manufacturer via an identification number. Barcodes remain the most commonly used symbology to identify product and facilitate inventory control. Machine readable devices e.g. barcodes or quick response $(\mathrm{QR})$ codes, and allow enhanced data checking and sharing of electronic data (Dabbene, Gay \& Tortia, 20132014). Over time, barcodes have evolved from the Universal Product Code (1D) to a 2D Quick Response (QR) code with high data storage capacity (Fang, Zhao, Warner \& Johnson, 2017; Yam, Takhistov \& Miltz, 2015). 1D barcodes are of value in terms of identifying the origin of the food and enable tracking and tracing (Table 5). 2D barcodes also allow 
consumers to use smart phone applications to determine product authenticity (Vukatana, Sevrani \& Hoxha, 2016). However, Lecat, Brouard \& Chapuis (20162017) argue that whilst the ease of integration, readability and direct marketing opportunities are high, conversely batch identification and security is low and a weakness of this technology.

\section{Take in Table 5}

Radio frequency identification (RFID) microchips are a more advanced data carrier compared to barcodes and have higher data storage capacity. RFID is used for product identification and traceability (Meraviglia, 2018) and information can be gathered automatically, without the need for visual scanning as with barcodes (Kumari, Narsaiah, Grewal \& Anurag, 2015; Bibi, Guillaume, Gontard \& Sorli, 2017). RFID technology uses radio waves in close proximity, to collect, store and manage information between the tag, reader and associated software. RFID is versatile as the tag can be incorporated into the packaging and allows reading through multiple materials (e.g. paper, plastic), is non-invasive and allows traceability over the whole distribution chain (Bibi, Guillaume, Gontard \& Sorli, 2017). Previous studies have utilized RFID in combination with Global Positioning System (GPS) and time-temperature indicators to monitor vehicles' location, temperature and unauthorized opening of vehicles' doors for food items served during the 2008 Beijing Olympics (Wu et al. 2010). However, the embedding of RFID tags in every product is expensive and impacts too on the ability to recycle packaging, although current research is seeking to reduce that cost (Aliaga et al. 2011; Bonaccorsi et al. 2017; Feng, Xie, Chen, \& Zheng, 2015; Wittkopf, Ge, Ionescu, Staehler, Pederson, \& Holder, 2018; Liegeard \& Manning, 2019). Barcodes and RFID are two of the most commonly used technologies in traceability and tracking. In fact, the application of RFID has extended from traceability to identification of individual units as counterfeiting risks can arise from perpetrators within the supply chain e.g. transporter, or importer (Przyswa, 2014b). Specific anti-counterfeiting technologies are now considered.

\subsection{Anti-counterfeiting technologies}

Anti-counterfeiting technologies are used to identify authentic products from fraudulent items. The technologies need to be difficult to duplicate, hard to re-use and yet easily applied and to identify 
visually, and easily noticeable when tampered with (Li, 2013). Anti-counterfeiting technologies for packaging can be divided into direct or overt technologies i.e. clearly visible to the consumer or indirect or covert technologies that are not visible to the naked eye (Meraviglia, 2018). Direct or overt technology enables end users to visually verify the originality of the packaging such as the use of holograms, watermarks, barcodes, RFID, and tamper-evident seals. Packaging technologies can be designed to be business-to-business (B2B) or business-to-consumer (B2C) anti-counterfeiting measures. At their simplest, packaging designs can incorporate tamper proof or tamper evident systems such as film wrappers, shrink seals and bands, breakable or single use caps (Zadbuke, Shahi, Gulecha, Padalkar \& Thube, 2013).

Whisky brands are using Near Field Communication (NFC) technology to ensure product integrity and maximize customers' satisfaction. The NFC tag is integrated with the label and consumers can simply tap their phone to the bottle's label to access product and brand information. The tag is applied in such a way that it will tear if the bottle's seal is broken (Connolly, 2015).

Holograms are often used as the first line of authentication in food products. A hologram generates rainbow-like radiance by diffracting white light into the spectrum of visible light and allow end users to view the holographic images directly (Lancaster, 2008). Gander (2015) suggests that holograms offer an essential layer of visible, overt brand protection and should not be overlooked by the food industry. One example of their use is Macallan Highland Single Malt Scotch Whisky where in the past fraudsters were re-using authentic whiskey bottles with intact labels and then selling the counterfeit product under their brand name. This type of fraud led to the utilization of a tamper evident, 3D holographic security label that sealed the capsule to the bottle. Once the cap is removed, the holographic security label would be destroyed, i.e. the label has tamper evident properties (Zadbuke, Shahi, Gulecha, Padalkar \& Thube, 2013), and so consumers can use this label to readily identify whether the whisky they are buying is authentic or not (DeLaRue, 2017). Holograms are cost-effective and cannot be copied easily. However, fraudsters have been known to manufacture their own holograms to use with counterfeit product (Kramer, 2006). Whilst RFID tags are hard to counterfeit, barcodes are not, so barcodes are often combined in anti-counterfeiting measures with technologies such as holograms or watermarks and sometimes with a covert technology too (Vukatana, Sevrani \& Hoxha, 2016). 
Watermarks are images or patterns that are embedded into packaging design and are visible when packaging is held up to light. Watermarks are often integrated into packaging to combat counterfeit products ( $\mathrm{Li}, 2013$ ). Food manufacturers can customise watermarks by using logos or brand names to authenticate their products (Consolidated Label, 2018). Visual watermarks are inexpensive, but business or consumer end-users must be aware of the watermark and know where to look in order to check that the product is authentic (Kramer, 2006).

Indirect or covert technology requires a certain level of expertise and dedicated equipment and the technology is often invisible e.g. ultraviolet (UV) inks (Cozzella, Simonetti, \& Spagnolo, 2012) or UV security threads (Zadbuke, Shahi, Gulecha, Padalkar \& Thube, 2013). A security thread is a plastic or metal ribbon that is embedded into paper fibre during the production process. The security thread is only visible in transmitted light and is a difficult feature to duplicate (Baldini, Fovino, Satta, Tsois \& Checchi, 2015; Li, 2013). Colorless fluorescence fibres are added during production process and the fluorescence artefact can then only be viewed under UV light (Baldini, Fovino, Satta, Tsois \& Checchi, 2015).

Covert technologies include special inks or chemical or mechanical methods (Li, 2013; Meraviglia, 2018). One example of covert technologies is invisible digital watermarks and microtext. The invisible digital watermark developed by FiligGrade can be embedded onto packaging and provide B2C product information via a mobile app which also verifies the accuracy of the watermark, thus the authenticity of the product (FiliGrade, n.d.). Microtext is extremely small texts or codes that is inserted into larger text, an overt image or another design and is not visible to the naked eye. This technique is very difficult to replicate as fraudsters are unaware that it exists and it requires advanced detection and printing technology to be used (Consolidated Label, 2018).

Thermochromatic ink changes color in response to changes in temperature. It is not only a useful anti-counterfeiting measure, but also it is important in indicating correct temperature storage and/or cumulative temperature abuse (Thermometer, 2018). The packaging is covered with heat-activated ink that irreversibly change from colorless to strong color alert such as blue, green, black or red (New Food, 2017). A color change on the packaging can identify if external logistics packaging had been tampered with or if the product has undergone temperature changes that affect product quality. The advantage of thermochromic ink is that it is safe to apply to food packaging and provides a strong visual cue to 
the consumer. However, fraudsters may have access to colour printing technology, hence manufacturers should not rely on color change as a sole anti-counterfeit strategy (Kramer, 2006).

Anti-counterfeiting technologies such as intaglio printing, security threads (described above) and fluorescence artifacts are often used for food products. Intaglio printing uses exceptionally fine lines and dots on flexible packaging and is one of the most difficult printing process to counterfeit ( $G+D$ Currency Technology, n.d.; Kenny, 2015; Bautista et al., 2017). These packaging technologies can also be combined in an anti-counterfeiting measures strategy with other forms of authentication in a concerted effort to minimize the risk of counterfeiting.

Knowledgeable and experienced consumers may be able to discern a fake from an authentic product. Whisky connoisseurs and experienced collectors can assess the label including the details it contains, and the condition of the cork (Woodward, 2017). Consumers are willing to use technology to self-authenticate food and beverage products (Charlebois, Schwab, Henn \& Huck, 2016). The use of digital technologies such as predictive computing and Internet of Things (IoT) applications give consumers a way to detect fraud in food stores, and this providse the consumer with greater personal agency. Most current anti-counterfeiting authentication techniques are designed for industrial and laboratory applications (Urickova \& Sadecka, 2015; Stupak, Goodall, Tomaniova, Pulkrabova \& Hajslova, 2018; Kamiloglu, 2019). Fixed or benchtop analytical devices could be based at major ports, distribution centres and transport hubs to test products to verify the risk of counterfeiting. The use of rapid, user-friendly handheld detection devices based on Raman spectroscopy (point-and-shoot) to detect food fraud (Ellis, Muhamadali, Haughey, Elliott, \& Goodacre, 2015) and Raman spectroscopy has been used to determine the properties of alcoholic beverages (Yang \& Ying, 2011) making the technique of interest in determining product authenticity (Manning \& Soon, 2014). Further options for developing integrity based techniques include: the use of isotope markers (Zadbuke, Shahi, Gulecha, Padalkar \& Thube, 2013); or biological and chemical markers known as "taggants" (Lecat, Brouard \& Chapuis, 2016). Chemical taggants are trace chemicals that are usually detected by highly specific reagent system rather than conventional analysis (Zadbuke, Shahi, Gulecha, Padalkar \& Thube, 2013) making them difficult to replicate by the food criminal. Biological taggants are incorporated at extremely low levels in products, coatings, or are applied to packaging components and identification again requires a highly specific reagent kit to authenticate the product (Zadbuke, Shahi, Gulecha, Padalkar \& Thube, 
2013). Thus combined with other smart IoT-based applications they can provide an effective anticounterfeiting measures that are bespoke to the product concerned.

\section{Discussion}

Food counterfeiting has a long history and has turned into a global, multi-million industry for fraudsters costing food and beverage supply chains dearly in terms of lost revenue, brand reputation, and in some cases causing fatalities to those who consume fake products. Recent fatal incidents associated with methanol and other toxic materials being used in counterfeit alcohol include 102 people dying in India in 2015 (BBC, 2015) and 86 dying in Indonesia in 2018 (Faridz \& Griffiths, 2018).

The Scotch whisky industry presents a reputable, world-famous product, often revered as one of the premium global spirits. As a premium product, it is also very attractive to counterfeiters. The industry, public authorities and researchers are working hard to mitigate against such activities through the use of anti-counterfeiting measures and also to detect counterfeit products should they occur. Similarly, fraudsters are thinking of new, innovative ways to avoid detection. Wilcock and Boys (2014) suggested an integrated approach to reduce counterfeits by adopting the following: (i) improved collaboration and sharing of intelligence within the food and beverage industry; (ii) involvement in anticounterfeiting measures by all members of the value chain from employees, suppliers to consumers and public authorities, and (iii) continuous improvement in product and packaging design. These measures are already adopted within the Scotch whisky industry. Intelligence sharing between the industry, whisky auctioneers and police successfully exposed and shutdown an illegal alcohol bottling operation (Paskin, 2017). Improved collaboration across the supply chain can help to detect early cases of counterfeiting and the sharing of intelligence between the industry and Europol has led to successful international raids such as those conducted during Operation Opson. These initiatives in the food and beverage industry should be strengthened further.

Counterfeiting can arise as a result of misrepresentation associated with firstly the product e.g. illegally produced and/or sub-standard alcoholic beverages being used to substitute for the premium product, secondly, process misrepresentation associated with the place or country of origin or the development of illicit supply networks, thirdly packaging misrepresentation with counterfeit packaging or the illicit use of recycled genuine liquor bottles and finally data misrepresentation through intentionally providing false information to accompany the batch of product (Manning, 2016). 
424 Continuous improvement in the type and confidence limits of analytical detection will make it more

425 difficult for perpetrators to produce and sell counterfeit whiskies without discovery. Packaging, and 426 smart technology in particular, plays a major role in combating food counterfeiting. Packaging

427 technologies are becoming more sophisticated and anti-counterfeit technologies are being designed so 428 that they are difficult to replicate (Vavra, 2015). Authentication and traceability systems underpin 429 product. In order to improve product safety and quality, and to protect brand value, food and beverage 430 companies should be prepared to invest more in monitoring, investigating and investing in intellectual 431 property registrations and protections and public relations that promote the consumers' role in tackling counterfeit products (Berman, 2005). Thus smart packaging technologies have a key role to play in wider anti-counterfeiting measures strategies.

\section{Conclusion}

This review has considered the typologies of counterfeiters and imitators and the opportunities for authenticating food products via either the product, the packaging or dual verification tools. Scotch whisky is used a case study, to demonstrate the significance and extent of global counterfeiting activities, their health risks and how the industry and public authorities have to improve their anticounterfeiting strategies. Although, there are various anti-counterfeiting approaches in place, counterfeiters are continuously finding new ways to replicate products and avoid detection. Most packaging-related anti-counterfeit technologies are stand-alone systems. A more holistic approach of designing physical hurdles to reduce the opportunity for counterfeiting and then developing artefactbased authentication systems that are coupled with traceability and tracking systems is essential. Thus, individual businesses, supply chains and regulators need to consider the kinds of integrated anticounterfeiting systems that are required to reduce counterfeiting and ultimately to protect food supply chains. 
Aliaga, C., B. M. Ferreira, M. Hortal, M., Pancorbo, Á., López, J.M. \& F.J. Navas, (2011). Influence of RFID tags on recyclability of plastic packaging. Waste management, 31(6), 1133-1138.

Aribarg, A., Arora, N., Henderson, T., \& Kim, Y. (2014). Private label imitation of a national brand: Implications for consumer choice and law. Journal of Marketing Research, 51(6), 657-675.

Aylott, R.I., \& MacKenzie, W.M. (2010). Analytical strategies to confirm the generic authenticity of Scotch Whisky. Journal of the Institute of Brewing, 116(3), 215-229.

Baldini, G., Fovino, I. N., Satta, R., Tsois, A. \& Checchi, E. (2015). Survey of techniques for the fight against counterfeit goods and IntellectualProperty Rights (IPR) infringement. European Commission JCR Technical Report, Eur 27688. Available at: https://core.ac.uk/download/pdf/38631802.pdf [Accessed 25 November 2018]

Bautista, L., Molina, L., Niembro, S., Garcia, J. M., Lopez, J. \& Vilchez, A. (2017). Coatings and inks for food packaging including nanomaterials. Emerging Nanotechnologies in Food Science: Micro and Nano Technologies, 149-173.

BBC (2018). Third of rare Scotch whiskies found to be fake. BBC News, 20 December. Available at: https://www.bbc.co.uk/news/uk-scotland-scotland-business-46566703 [Accessed 22 December 2018]

BBC (2015). India alcohol poisoning: Mumbai death toll tops 100. Available at: https://www.bbc.co.uk/news/world-asia-india-33224514 [Accessed 22 December 2018]

BBC (2011). Leicestershire fake vodka gang jailed. Available at: https://www.bbc.co.uk/news/ukengland-leicestershire-15888342 [Accessed 9 February 2019]

Berman, B. (2008). Strategies to detect and reduce counterfeiting activity. Business Horizons, 51(3), 191-199.

Bian, X., \& Moutinho, L. (2009). An investigation of determinant of purchase consideration. Journal of Business Research, 62, 368-378.

Bibi, F., Guillaume, C., Gontard, N. \& Sorli, B. (2017). A review: RFID technology having sensing aptitudes for food industry and their contribution to tracking and monitoring of food products. Trends in Food Science \& Technology, 62, 91-103.

Bodner, D. A. (2014). Enterprise modeling framework for counterfeit parts in defense systems. Procedia Computer Science, 36, 425-431.

Bonaccorsi, M., S. Betti, G. Rateni, D. Esposito, A. Brischetto, M. Marseglia, P. Dario, \& F. Cavallo, (2017). 'HighChest': An Augmented Freezer Designed for Smart Food Management and Promotion of Eco-Efficient Behaviour. Sensors, 176), 1357-78

Cesareo, L. (2016). Counterfeiting and piracy. A comprehensive literature review. New York, NY: Springer.

Cesareo, L., \& Stöttinger, B. (2015). United we stand, divided we fall: How firms can engage consumers in their fight against counterfeits. Business Horizons, 58(5), 527-537.

Charlebois, S., Schwab. A., Henn, R., \& Huck, C.W. (2016). Food fraud: An exploratory study for measuring consumer perception towards mislabelled food products and influence on selfauthentication intentions. Trends in Food Science \& Technology, 50, 211-218.

Connolly, K. B. (2015). Johnnie Walker 'smart bottle' performs for consumers and supply chain. Packaging Digest. Available at: https://www.packagingdigest.com/beverage-packaging/johnniewalker-smart-bottle-performs-for-consumers-and-supply-chain150306 [Accessed 22 December 2018] 
Consolidated Label (2018). Anti-counterfeit labels and packaging are key to brand protection. Available at: https://www.consolidatedlabel.com/label-articles/anti-counterfeit-labels/ [Accessed 15 November 2018]

Cozzella, L., Simonetti, C. \& Spagnolo, G. S. (2012). Drug packaging security by means of white-light speckle. Optics and Lasers in Engineering, 50(10), 1359-1371.

Dabbene, F., Gay, P., \& Tortia, C. (2014). Traceability issues in food supply chain management: A review. Biosystems engineering, 120, 65-80.

DeLaRue (2017). Case study. Macallan Whiskey picks Izon® Technology as part of a comprehensive anti-counterfeit solution. Available at: https://cdn2.hubspot.net/hubfs/2752422/Adwords\%20Landing\%20Pages/DLR_Izon_Macallan_Whisky _case_study_v5.pdf?t=1542991180152 [Accessed 25 November 2018]

Ellis, D. I., Muhamadali, H., Haughey, S. A., Elliott, C. T., \& Goodacre, R. (2015). Point-and-shoot: rapid quantitative detection methods for on-site food fraud analysis - moving out of the laboratory and into the food supply chain. Analytical Methods, 7(22), 9375-9716.

Fang, Z., Zhao, Y., Warner, R. D. \& Johnson, S. K. (2017). Active and intelligent packaging in meat industry. Trends in Food Science and Technology, 61, 60-71.

Faridz, D. \& Griffiths, J. (2018), More than 80 dead from drinking bootleg alcohol in Indonesia, Available at: https://edition.cnn.com/2018/04/12/health/indonesia-fake-alcohol-int//index.html [Accessed 22 December 2018].

Feng, Y., Xie, L., Chen, Q., \& Zheng, L. R. (2015). Low-cost printed chipless RFID humidity sensor tag for intelligent packaging. IEEE Sensors Journal, 15(6), 3201-3208.

FiliGrade (n.d.). Invisible watermarks is a solution. Available at: http://www.filigrade.com/watermarksolutions/product-info [Accessed 25 November 2018]

Fogel, R.A. (1986). Grey market goods and modern international commerce: a question of free trade. Fordham Int'/ $L, 10,308-337$

Folinas, D., Manikas, I., \& Manos, B. (2006), 'Traceability data management for food chains', British Food Journal, 108(8), 622-633

Food Crime Annual Strategic Assessment (FCASA, 2016). Available at: https://www.food.gov.uk/sites/default/files/media/document/fsa-food-crime-assessment-2016.pdf [Accessed on 10 December 2018]

G+D Currency Technology (n.d.) Print effects to improve aesthetics and security. Available at: https://www.gi-de.com/en/gb/currency-technology/solutions/banknote-security/printed-securityfeatures/ [Accessed 25 November 2018]

Gander, P. (2015). Holograms overlooked for security. Food Manufacture, available at: https://www.foodmanufacture.co.uk/Article/2015/06/25/Food-firms-shouldn-t-overlook-holograms [Accessed 25 November 2018]

Gentry, J. W., Putrevu, S., \& Shultz, C. J., II (2006). The effects of counterfeiting on consumer search. Journal of Consumer Behaviour, 5(3), 245-256.

Grossman, G. M., \& Shapiro, C. (1988). Foreign counterfeiting of status goods. The Quarterly Journal of Economics, 103(1), 79-100. 
Hopkins, D. M., Kontnik. L. T., \& Turnage, M. T. (2003). Chapter 12. Anticounterfeiting technology solutions. In, Counterfeiting Exposed: Protecting your Brand and Customers. New Jersey: John Wiley \& Sons, pp. 249-262.

Interpol (2018). Deadly and dangerous fake food and drink seized in global operation. Available at: https://www.interpol.int/en/News-and-media/News/2018/N2018-033 [Accessed 18 December 2018]

Interpol-Europol (2016). Report Operation OPSON V. Available at:

https://www.europol.europa.eu/sites/default/files/documents/report opson v.pdf [Accessed 18 December 2018]

Kamiloglu, S. (2019). Authenticity and traceability in beverages. Food Chemistry, 277, 12-24.

Kapferer, J. N. (1995). Brand confusion: empirical study of a legal concept. Psychology \& Marketing, $12(6), 551-568$.

Kaufmann, H. R., Petrovici, D. A., Gonçalves Filho, C., \& Ayres, A. (2016). Identifying moderators of brand attachment for driving customer purchase intention of original vs counterfeits of luxury brands. Journal of Business Research, 69(12), 5735-5747.

Kenny, J. (2015). The pursuit of security packaging. Available at: https://www.labelandnarrowweb.com/issues/2016-07-01/view_front_row/the-pursuit-of-securitypackaging [Accessed 25 November 2018]

Kim, Y. G. \& Woo, E. (2016). Consumer acceptance of a quick response (QR) code for the food traceability system: Application of an extended technology acceptance model (TAM). Food Research International, 85, 266-272.

Kramer, U. (2006). Counterfeiting in the People's Republic of China. Analysis of Impact, Drivers and Containment Options concerning increased Counterfeiting. Diploma Thesis. Diplomica Verlag, GmbH

Kuballa, T., Hausler, T., Okaru, A.O., Neufeld, M., Abuga, K.O., Kibwage, I.O., Rehm, J., Luy, B., Walch, S.G. \& Lachenmeier, D.W., (2018). Detection of counterfeit brand spirits using 1 H NMR fingerprints in comparison to sensory analysis. Food chemistry, 245, 112-118.

Kumari, L., Narsaiah, K., Grewal, M. K. \& Anurag, R. K. (2015). Application of RFID in agri-food sector. Trends in Food Science \& Technology, 43(2), 144-161.

Lancaster, I. (2008). Trends: Holograms and anticounterfeiting. Pharmaceutical Technology, 32(4), available at: http://www.pharmtech.com/trends-holograms-and-anticounterfeiting [Accessed 20 November 2018]

Lavin, K. (2013). Protecting your wine - and your winery's reputation. Wines \& Vines. Available at: https://www.winesandvines.com/news/article/120550/Protecting-Your-Wine-And-Your-WinerysReputation [Accessed 4 December 2018]

Lecat, B., Brouard, J., \& Chapuis, C. (2017). Fraud and counterfeit wines in France: an overview and perspectives. British Food Journal, 119(1), 84-104.

Le Roux, A., Bobrie, F., \& Thébault, M. (2016). A typology of brand counterfeiting and imitation based on a semiotic approach. Journal of Business Research, 69(1), 349-356.

Li, L. (2013). Technology designed to combat fakes in the global supply chain. Business Horizons, $56(2), 167-177$.

Liegeard, J. \& Manning, L. (2019) Using intelligent applications to reduce consumer food waste, Critical Reviews in Food Science and Nutrition, https://www.tandfonline.com/doi/full/10.1080/10408398.2018. 
606

607

608

609

610

611

612

613

614

615

616

617

618

619

620

621

622

623

624

625

626

627

628

629

630

631

632

633

634

635

636

637

638

639

640

641

642

643

644

645

646

647

648

649

650

651

Manning L. (2019), Food defence: refining the taxonomy of food defence threats, Trends in Food Science and Technology, 85, 107-115,

Manning, L. (2016). Food fraud: policy and food chain. Current Opinion in Food Science, 10, 16-21.

Manning, L \& Soon, J.M, (2014) Developing systems to control food adulteration, Food Policy, 49 (1), 23-32

Meraviglia, L. (2018). Technology and counterfeiting in the fashion industry: Friends or foes? Business Horizons, 61(3), 467-475

Nanomatrixsecure,com (nd) Security Planchettes. Available at:

https://www.nanomatrixsecure.com/en/security-products/security-features/security-paperconsumables/security-planchettes [Accessed on 10 December 2018]

New Food (2017). American firm turns up the dial on heat-activated ink. New Food, available at: https://www.newfoodmagazine.com/news/44106/heat-activated-ink/ [Accessed 25 November 2018]

Paskin, B. (2017). 'Sophisticated' fake whisky setup exposed. Available at:

https://scotchwhisky.com/magazine/latest-news/12984/sophisticated-fake-whisky-setup-exposed/ [Accessed 18 December 2018]

Phau, I., Sequeira, M., \& Dix, S. (2009). Consumers' willingness to knowingly purchase counterfeit products. Direct Marketing: An International Journal, 3(4), 262-281.

Phillips, T. (2007). Knockoff: The Deadly Trade in Counterfeit Goods: The True Story of the World's Fastest Growing Crimewave. Kogan Page Publishers.

Przyswa, E. (2014a). Counterfeiting in the wines and spirits market: Key issues and presentation of anti-counterfeiting technologies. Available at:

https://www.researchgate.net/profile/Eric Przyswa/publication/263016723 Counterfeiting in the wi nes and spirits market Key issues and presentation of anti-

counterfeiting technologies/links/00b49539976b432ac7000000/Counterfeiting-in-the-wines-andspirits-market-Key-issues-and-presentation-of-anti-counterfeiting-technologies.pdf [Accessed 4

December 2018]

Przyswa, E. (2014b). Protecting your wine: Stop counterfeiters from selling cheap imitations of your premium brand. Available at: Wines \& Vines, August 2014, 38-42. Available at:

https://www.winesandvines.com/digitaledition/ [Accessed 4 December 2018]

Qin, Y., Shi, L. H., Song, L., Stöttinger, B., \& Tan, K. F. (2018). Integrating consumers' motives with suppliers' solutions to combat Shanzhai: A phenomenon beyond counterfeit. Business Horizons, 61(2), 229-237.

Ringsberg, H. (2014), Perspectives on food traceability: a systematic literature review, Supply Chain Management: An International Journal, 19(5/6), 558-576.

SafeProof (2018a), Refilling Liquor Bottles, Available at: https://www.safeproof.org/refilling-liquorbottles/ [Accessed 9 February 2019]

SafeProof (2017) Liquor in Counterfeit Bottles, Available at: https://www.safeproof.org/counterfeitliquor-bottles/ [Accessed 9 February 2019]

Scotch Whisky Association (n.d.). About the SWA. Available at: http://www.scotchwhisky.org.uk/what-we-do/ [Accessed 18 December 2018] 
Scotch Whisky Regulations (2009). Definition of "Scotch Whisky" and categories of Scotch Whisky. 2009 No. 2980, Regulation 3. Available at: http://www.legislation.gov.uk/uksi/2009/2890/regulation/3/made [Accessed 18 December 2018]

Shand, C. A., Wendler, R., Dawson, L., Yates, K., \& Stephenson, H. (2017). Multivariate analysis of Scotch whisky by total reflection $\mathrm{x}$-ray fluorescence and chemometric methods: A potential tool in the identification of counterfeits. Analytica chimica acta, 976, 14-24.

Snowdon, C. (2012). Drinking in the shadow economy. Available at: https://iea.org.uk/wpcontent/uploads/2016/07/drinking\%20in\%20the\%20Shadow\%20Economy 0.pdf (Accessed 5 December 2018)

Soon, J.M., Manning, L. \& Smith, R. (2019) Advancing understanding of pinchpoints and crime prevention in the food supply chain, Crime Prevention and Community Safety, 21(1), 1-19

Soon, J.M \& Manning, L. (2018), Food smuggling and trafficking: The key factors of influence, Trends in Food Science and Technology, 81, 132-138

Soon, T. J. (2008). QR code. Synthesis Journal, 2008, 59-78.

Spink, J., Moyer, D.C. Park, H. Wu, Y. Fersht, V. Shao, B., Hong, M., Paek, S.Y., \& Edelev, D. (2015), Introduction to Food Fraud including translation and interpretation to Russian, Korean and Chinese languages. Food Chemistry. 189, 102-107.

Staake, T., Thiesse, F., \& Fleisch, E. (2012). Business strategies in the counterfeit market. Journal of Business Research, 65(5), 658-665.

Statista (2019), Whiskey Industry - Statistics \& Facts, Available from:

https://www.statista.com/topics/3770/whiskey-industry/ [Accessed: 9 February 2019]

Stupak, M., Goodall, I., Tomaniova, M., Pulkrabova, J., \& Hajslova, J. (2018). A novel approach to assess the quality and authenticity of Scotch Whisky based on gas chromatography coupled to high resolution mass spectrometry. Analytica Chimica Acta, 1042, 60-70.

Takahashi, M., Nagata, M., \& Miura, N. (2018). Supply-Chain Security Enhancement by Chaotic Wireless Chip-Package-Board Interactive PUF. In 2018 IEEE 68th Electronic Components and Technology Conference (ECTC), 521-526.

Thaichon, P., \& Quach, S. (2016). Dark motives-counterfeit purchase framework: Internal and external motives behind counterfeit purchase via digital platforms. Journal of Retailing and Consumer Services, 33, 82-91.

The Global Brand Counterfeiting Report (2018). Available at: https://www.researchandmarkets.com/research/7j7l2n/global brand?w=4 [Accessed 09 December 2018]

Thermometer (2018). Color change inks. Available at: https://www.thermometersite.com/colorchange-inks [Accessed 25 November 2018]

Ting, M. S., Goh, Y. N., \& Isa, S. M. (2016). Determining consumer purchase intentions toward counterfeit luxury goods in Malaysia. Asia Pacific Management Review, 21(4), 219-230.

Tobiassen, R.M. (2014) The "Fake Alcohol" Situation in the United States: The Impact of Culture, Market Economics, and the Current Regulatory Systems. Available at: https://www.centerforalcoholpolicy.org/wpcontent/uploads/2015/04/The Fake Alcohol Situation in the United-States compressed.pdf [Accessed 20 December 2018] 
696 UK Customs and Excise Management Act (1979) Available at:

697 https://www.legislation.gov.uk/ukpga/1979/2/section/170 [Accessed 9 February 2019]

698 Urickova, V. \& Sadecka, J. (2015). Determination of geographical origin of alcoholic beverages using 699 ultraviolet, visible and infrared spectroscopy: A review. Spectrochimica Acta Part A: Molecular and 700 Biomolecular Spectroscopy, 148, 131-137.

701 Van Horen, F., \& Pieters, R. (2012). Consumer evaluation of copycat brands: The effect of imitation 702 type. International Journal of Research in Marketing, 29(3), 246-255.

703 Vavra, C. (2015). Packaging's role in food fraud prevention. Control Engineering. Available at: 704 https://www.controleng.com/articles/packagings-role-in-food-fraud-prevention/ [Accessed 22 705 December 2018]

Vieira, R., Silva, C., Antunes, M., \& Assis, A. (2016). Information system for automation of counterfeited documents images correlation. Procedia Computer Science, 100, 421-428.

Vukatana, K., Sevrani, K., \& Hoxha, E. (2016). Anti-Counterfeiting Technologies in Albanian Food Industry, Review of Business and Finance Studies 7(2), 101-106

Wikimedia commons (2015). Aztec. Available at: https://commons.wikimedia.org/wiki/File:Aztec_wikipedia.png [Accessed 15 November 2018]

Wikimedia commons (2016a). PDF 417. Available at: https://commons.wikimedia.org/wiki/File:PDF417_Example.svg [Accessed 15 November 2018]

Wikimedia commons (2016b). QR Code. Available at: https://commons.wikimedia.org/wiki/File:QR_Code_Model_1_Example.svg [Accessed 15 November 2018]

Wikimedia commons (2017). UPC barcode. Available at: https://commons.wikimedia.org/wiki/File:UPC-A_Barcode.svg [Accessed 15 November 2018]

Wikimedia commons (2018). Databar. Available at:

https://commons.wikimedia.org/wiki/File:Databar_14_00075678164125.png [Accessed 15 November 2018]

Wilcock, A. E., \& Boys, K. A. (2014). Reduce product counterfeiting: An integrated approach. Business horizons, 57(2), 279-288.

Wilcox, K., Kim, H. M., \& Sen, S. (2009). Why do consumers buy counterfeit luxury brands? Journal of Marketing Research, 46, 247-259

Wimmer, H., \& Yoon, V. Y. (2017). Counterfeit product detection: Bridging the gap between design science and behavioral science in information systems research. Decision Support Systems, 104, 1-12.

Wittkopf, J., Ge, N., Ionescu, R., Staehler, W., Pederson, D., \& Holder, H. (2018). Chipless RFID with fully inkjet printed tags: A practical case study for low cost smart packaging applications. In 2018 IEEE 68th electronic components and technology conference (ECTC), 940-947

Woodward, R. (2017). $\$ 10,000$ glass of Macallan 'is a fake'. Available at: https://scotchwhisky.com/magazine/latest-news/15511/10-000-glass-of-macallan-is-a-fake/ [Accessed 18 December 2018]

WTO (1994), Agreement on Trade-Related Aspects of Intellectual Property Rights, Annex 1C of the Marrakesh Agreement Establishing the World Trade Organization, Available at http://www.wto.org/english/docs e/legal e/27-trips.pdf. [Accessed on 28 December 2018] 
Wu, X., Wu, H., Xia, L., Ji, K., Liu, Z., Chen, J. Hu, D. Gao, C. \& Wu, Y. (2010). Socio-technical innovations for total food chain safety during the 2008 Beijing Olympics and Paralympics and beyond. Trends in Food Science \& Technology, 21(1), 44-51.

Wu, C. W., Gong, J. C., \& Chiu, H. H. (2016). Duopoly competition with non-deceptive counterfeiters. International Review of Law and Economics, 47, 33-40.

Yam, K. L., Takhistov, P. T. \& Miltz, J. (2005). Intelligent packaging: Concepts and applications. Journal of Food Science, 70(1), R1-R10.

Yang, D., \& Ying, Y. (2011). Applications of Raman spectroscopy in agricultural products and food analysis: A review. Journal of Applied Spectroscopy Reviews, 46(7), 539-560.

Yao J_T. (2005) Counterfeiting and an optimal monitoring policy. Eur J taw Econ European Journal of Law and Economics 19(1), 95-114.

Yao, J. T. (2015). The impact of counterfeit-purchase penalties on anti-counterfeiting under deceptive counterfeiting. Journal of Economics and Business, 80, 51-61.

Yoo, B., \& Lee, S. H. (2005). Do counterfeits promote original products? Hempstead, NY: Hofstra University.

Zadbuke, N., Shahi, S., Gulecha, B., Padalkar, A., \& Thube, M. (2013). Recent trends and future of pharmaceutical packaging technology. Journal of pharmacy \& bioallied sciences, 5(2), 98.

Zaichkowsky, J.L. (2006), The Psychology Behind Trademark Infringement and Counterfeiting.

Mahwah, NJ: Lawrence Erlbaum Associates.

Table 1. Recent UK counterfeiting incidents associated with alcohol (Adapted from: FCASA, 2016; Paskin, 2017)

\begin{tabular}{l}
\hline Recent UK counterfeiting incidents associated with alcohol \\
\hline - Over 35,000 counterfeit bottles of a vodka brand, made in Ukraine, seized at Dover in April \\
2014; \\
Over 20,000 counterfeit bottles for a vodka brand seized from premises in Derbyshire in \\
November 2014, alongside material suggesting adulteration with antifreeze; \\
- The seizure in Harlow of nearly 8,000 litres of vodka from Lithuania with forged duty stamps in \\
June 2015; \\
- 130,000 litres of potentially toxic spirits found in Cheshire in July/August 2015, alongside \\
material to facilitate its bottling and packaging; and \\
- A fake whisky bottling operation uncovered in London in 2017 where hundreds of old bottles of \\
whisky, rum and other spirits were refilled with cheaper liquids
\end{tabular}

Table 2. Typology of imitators and counterfeiters (Adapted from Staake et al. 2012; Vimmer and Yoon, 2017)

\begin{tabular}{|c|c|c|c|c|c|}
\hline & $\begin{array}{l}\text { Imitators or } \\
\text { copycats }\end{array}$ & Fraudster & Desperados & $\begin{array}{l}\text { Disaggregato } \\
\text { rs }\end{array}$ & Smugglers \\
\hline Capabilities & $\begin{array}{l}\text { Solid re- } \\
\text { engineering } \\
\text { and } \\
\text { engineering } \\
\text { skills. }\end{array}$ & $\begin{array}{l}\text { Some } \\
\text { production } \\
\text { capabilities }\end{array}$ & $\begin{array}{l}\text { Ability to } \\
\text { conceal illicit } \\
\text { activities }\end{array}$ & $\begin{array}{l}\text { Established } \\
\text { production } \\
\text { network for } \\
\text { counterfeit } \\
\text { products or can } \\
\text { develop own } \\
\text { production skill. }\end{array}$ & $\begin{array}{l}\text { Manage } \\
\text { network of } \\
\text { criminal } \\
\text { actors } \\
\text { Money } \\
\text { laundering }\end{array}$ \\
\hline
\end{tabular}




\begin{tabular}{|c|c|c|c|c|c|}
\hline & $\begin{array}{l}\text { Extended } \\
\text { production } \\
\text { capability }\end{array}$ & & & $\begin{array}{l}\text { Flexibility - able } \\
\text { to follow new } \\
\text { trends quickly }\end{array}$ & \\
\hline \multirow[t]{3}{*}{ Business model } & $\begin{array}{l}\text { Brand imitation } \\
\text { as accelerator. } \\
\text { Compatible } \\
\text { products at low } \\
\text { price for }\end{array}$ & $\begin{array}{l}\text { Brand } \\
\text { counterfeitin } \\
\mathrm{g} \text { as enabler } \\
\text { of illicit } \\
\text { goods. }\end{array}$ & $\begin{array}{l}\text { Brand } \\
\text { counterfeiting } \\
\text { as enabler for } \\
\text { selling } \\
\text { dangerous } \\
\text { goods. }\end{array}$ & $\begin{array}{l}\text { Brand } \\
\text { counterfeiting } \\
\text { as dominant } \\
\text { source of } \\
\text { income }\end{array}$ & $\begin{array}{l}\text { Brand } \\
\text { counterfeitin } \\
\mathrm{g} \text { to improve } \\
\text { market } \\
\text { access. }\end{array}$ \\
\hline & $\begin{array}{l}\text { functionality. } \\
\text { Intent to } \\
\text { engage the } \\
\text { consumer in } \\
\text { terms of the } \\
\text { association }\end{array}$ & \multirow[t]{2}{*}{$\begin{array}{l}\text { Deceit of } \\
\text { customer. }\end{array}$} & $\begin{array}{l}\text { Target } \\
\text { expensive but } \\
\text { easily } \\
\text { mimicked } \\
\text { product. }\end{array}$ & \multirow[t]{2}{*}{$\begin{array}{l}\text { Serve } \\
\text { customers' } \\
\text { desire to signal } \\
\text { wealth and } \\
\text { status. }\end{array}$} & \multirow[t]{2}{*}{$\begin{array}{l}\text { Evading } \\
\text { taxes or } \\
\text { levies or } \\
\text { selling } \\
\text { stolen items. }\end{array}$} \\
\hline & $\begin{array}{l}\text { between brand } \\
\text { and imitation } \\
\text { product. This } \\
\text { can lead to } \\
\text { confusion. }\end{array}$ & & $\begin{array}{l}\text { Deceit of } \\
\text { customer. }\end{array}$ & & \\
\hline \multirow[t]{2}{*}{ Strategic focus } & $\begin{array}{l}\text { Competitive } \\
\text { advantage. }\end{array}$ & $\begin{array}{l}\text { Profit } \\
\text { orientation } \\
\text { opportunism }\end{array}$ & $\begin{array}{l}\text { Maximum } \\
\text { profit } \\
\text { orientation }\end{array}$ & \multirow{2}{*}{$\begin{array}{l}\text { Flexibility } \\
\text { Focus on goods } \\
\text { with high } \\
\text { demand }\end{array}$} & \multirow{5}{*}{$\begin{array}{l}\text { Extend } \\
\text { power in } \\
\text { criminal } \\
\text { network } \\
\text { Established } \\
\text { structures, } \\
\text { long term } \\
\text { orientation } \\
\text { Cigarettes }\end{array}$} \\
\hline & $\begin{array}{l}\text { Entrepreneursh } \\
\text { ip }\end{array}$ & - & $\begin{array}{l}\text { with an } \\
\text { absence of } \\
\text { ethical } \\
\text { standards }\end{array}$ & & \\
\hline $\begin{array}{l}\text { Typical } \\
\text { products }\end{array}$ & $\begin{array}{l}\text { Fast moving } \\
\text { consumer } \\
\text { goods }\end{array}$ & $\begin{array}{l}\text { Perfume and } \\
\text { cosmetics }\end{array}$ & $\begin{array}{l}\text { Pharmaceutic } \\
\text { al products }\end{array}$ & $\begin{array}{l}\text { Watches and } \\
\text { jewellery }\end{array}$ & \\
\hline Functionality & $\begin{array}{l}\text { High visual and } \\
\text { functional } \\
\text { quality - fulfil } \\
\text { needs of the } \\
\text { user }\end{array}$ & $\begin{array}{l}\text { High visual } \\
\text { but low } \\
\text { functional } \\
\text { quality i.e. } \\
\text { not } \\
\text { functionally } \\
\text { equivalent. }\end{array}$ & $\begin{array}{l}\text { Quality low } \\
\text { and difficult } \\
\text { to evaluate } \\
\text { by consumer } \\
\text { before } \\
\text { purchase. }\end{array}$ & $\begin{array}{l}\text { Average quality } \\
\text { Low to average } \\
\text { complexity }\end{array}$ & \\
\hline & & & $\begin{array}{l}\text { May be } \\
\text { harmful to } \\
\text { the } \\
\text { consumer. }\end{array}$ & & \\
\hline \multirow[t]{2}{*}{$\begin{array}{l}\text { Countermeasur } \\
\text { es }\end{array}$} & $\begin{array}{l}\text { Produced on } \\
\text { large scale so } \\
\text { vulnerable to } \\
\text { product seizure } \\
\text { because they } \\
\text { have high } \\
\text { levels of capital } \\
\text { involved. }\end{array}$ & $\begin{array}{l}\text { Prevent } \\
\text { access to } \\
\text { legitimate } \\
\text { supply } \\
\text { chains }\end{array}$ & $\begin{array}{l}\text { Produce on } \\
\text { small scale. } \\
\text { Improve } \\
\text { consumer } \\
\text { awareness of } \\
\text { counterfeit } \\
\text { products. }\end{array}$ & \multirow[t]{2}{*}{$\begin{array}{l}\text { Improve } \\
\text { consumer } \\
\text { awareness of } \\
\text { counterfeit } \\
\text { products }\end{array}$} & \multirow[t]{2}{*}{$\begin{array}{l}\text { Often have } \\
\text { an illicit } \\
\text { supply chain } \\
\text { that can be } \\
\text { difficult to } \\
\text { infiltrate }\end{array}$} \\
\hline & $\begin{array}{l}\text { Often sold in } \\
\text { legitimate } \\
\text { chains so } \\
\text { supply chain } \\
\text { governance can }\end{array}$ & & & & \\
\hline
\end{tabular}




\begin{tabular}{ll}
\hline be introduced \\
to prevent \\
deception. \\
Many brand \\
owners may \\
not be \\
prepared to \\
engage with \\
private label \\
retailers via \\
litigation.
\end{tabular}

778 Table 3. Socio-economic factors that influence counterfeiting (Adapted from Bodner, 2014)

\begin{tabular}{l} 
Factors \\
\hline Increased systems complexity \\
Weak governance of intellectual \\
property (IP) \\
Globalisation of supply chains
\end{tabular}

Outsourcing of services including design and manufacturing

Use of internet as a purchasing platform

Decreased cost of counterfeits versus the genuine article

\section{Countermeasures}

Legislation and law enforcement that addresses counterfeiting.

Supplier procurement procedures that address intellectual property management and counterfeiting.

Obsolescence management and re-alignment of new processes and products to reduce the risk of counterfeiting.

Risk assess and mitigate the outsourcing of critical processes or critical part-product or finished product manufacture.

Traceability procedures for components and products including the use of smart packaging technologies.

Testing programmes using analysis methods that can detect counterfeiting.

Cyber management protocols and training.

Horizon scan for potential counterfeits and the methods that are being used to produce them. Develop and implement an anti-counterfeiting strategy.

780 Table 4. Different types of ACMs. Adapted from (Cesareo and Stöttinger, 2015; Wilcox and Boys, 781 2014; Qin et al. 2018).

\begin{tabular}{lcl}
\hline ACM Type & Examples of countermeasure \\
\hline $\begin{array}{l}\text { Communication- } \\
\text { related ACMs }\end{array}$ & Communications that focus on the quality and appearance of the original \\
to make consumers aware of the difference between the original and \\
fraudulent versions i.e. how to spot fakes. \\
- $\quad$ Drive word of mouth (WoM) communication about original features. \\
- $\quad$ Communications that focus on why the original product commands the \\
price that it does. \\
Promote the relationship between the brand-firm and the consumer. \\
Communications should reinforce that purchasing counterfeits is \\
unlawful and unethical, the role of criminal and criminal gangs, and its \\
impact on society (poor health and welfare of workers, human slavery, \\
bonded labour) and with food the potential health and safety risks e.g.
\end{tabular}


death from consuming counterfeit alcohol containing methanol) and the consequences to legitimate companies (bankruptcy, job losses) and the loss of tax revenue and its impact on hospitals, schools etc.

Distribution related ACMs
- Provide consumers with warranties and after sales service if they purchase the original.

- Provide information on the authorised retailers that sell the original and also implement a seller verification programme so that they can be checked for compliance.

- Introduce traceability systems and a loss prevention programme that operates at supply chain level. This should include a supplier auditing programme.

- Develop a product disposal procedure that limits the potential for substandard products to be sold in grey networks.

- Display certification within authorized retailers.

- Limit sales or if operating in those environments develop specific integrity protocols for regions or supply chains known to be corrupt.

Price related $\quad-\quad$ Reduce price gaps by introducing lower price product entry lines.

ACMS - Review and reduce market, transaction and production costs to minimize risk of others undercutting the cost of the product.

Product related $\quad$ - Differentiate authentic products as much as possible and stress ACMs genuineness e.g. using distinct labelling, serial numbers, codes and packaging features.

- Differentiate between tangible product quality benefits (labour, taste, durability) and intangible product quality benefits (prestige, image, social acceptance)

- Authentication certificates and technologies that are difficult to replicate.

- Ensure authentic product purchase allows access to additional consumer benefits e.g. lower prices.

- Provide functional benefits that are not easily reproduced and drive product innovation to limit the ability of others to produce Shanzhai products.

- Protect products by protecting core technology and not outsource the entire manufacturing process.

Social value $\quad$ - Create a discourse that considers buying imitations as harmful.

related ACMs - Promote the intangible benefits of the brand through building exclusive communities.

Management system related ACMs

- Ensure that the organisation's quality policy and quality objectives refer to and integrate an anti-counterfeiting strategy.

- Establish clear leadership and senior management commitment both within and external to the business that addresses anti-counterfeiting protocols.

- Ensure product development strategies recognise the need to develop anti-counterfeiting measures and ensure there is a continuous product evolution process to make counterfeiting more difficult.

- Develop employee awareness and training programmes that focus on IP rights, and how to tell legitimate and counterfeit products the value (economic and social) of anti-counterfeiting strategies to the business and consumers .

- Ensure employees are aware of reporting structures for identifying and addressing counterfeiting activity.

Table 5. Examples of barcodes

\section{Barcodes}

Names

Characteristics 


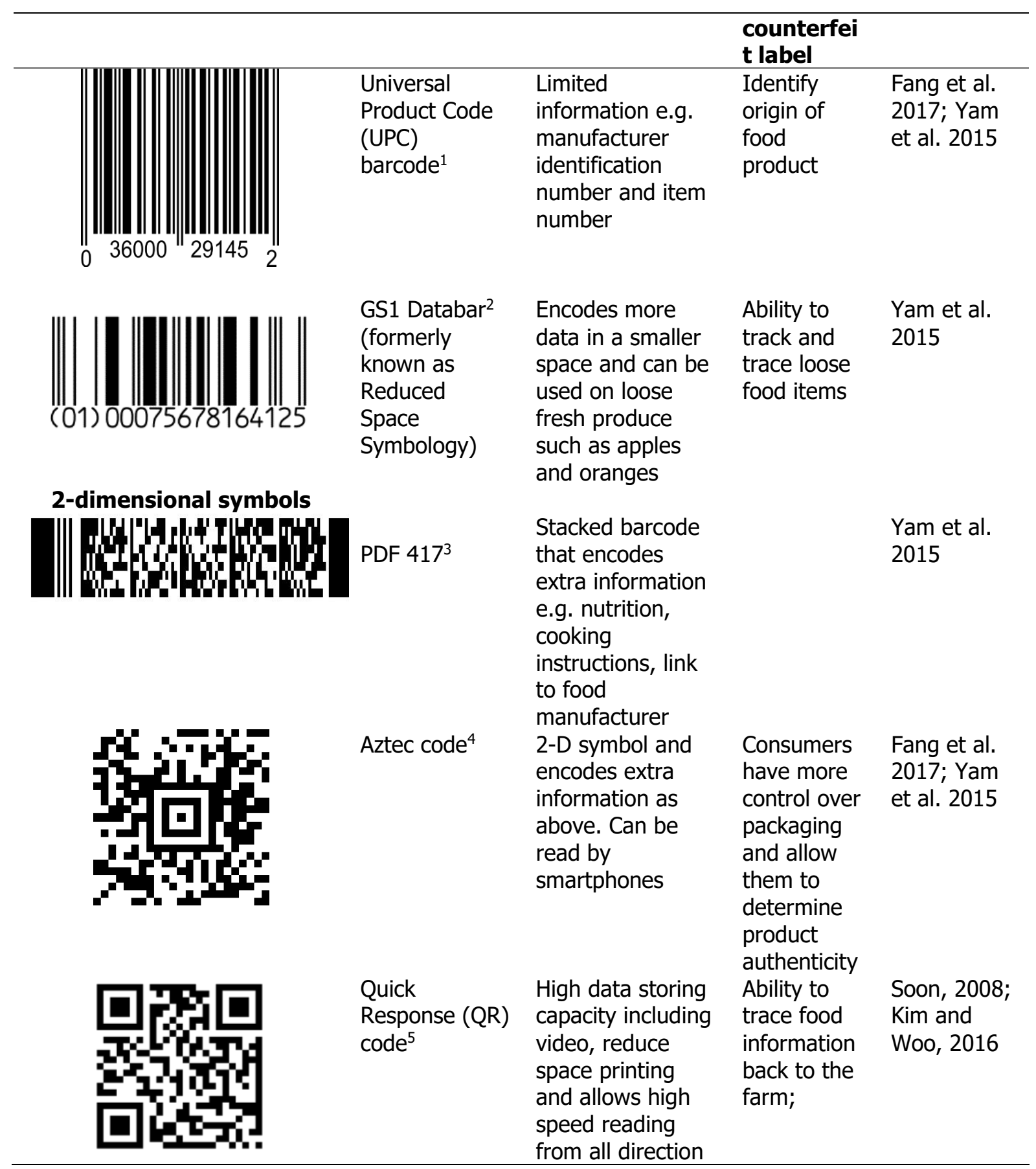

Note: ${ }^{1-5}$ Wikimedia commons 2015, 2016a, 2016b, 2017, 2018 
795

796

\section{Typology of counterfeiting}

- Substitution (of product or packaging)

- Over-run (Third shift illicit Production)

- Duplication (Tear-down)

- Tampering (interfering with packaging)

- Imitation (non-deceptive or Deceptive)

- Malicious counterfeiting (forces product failure)

- Document counterfeiting

\section{Key anti-counterfeiting measures (ACMs)}

- Legislation and law enforcement that addresses counterfeiting.

- Supplier procurement procedures that address intellectual property management and counterfeiting.

- Obsolescence management and re-alignment of new processes and products to reduce the risk of counterfeiting.

- Risk assess and mitigate the outsourcing of critical processes or critical part-product or finished product manufacture.

- Traceability procedures for components and products including the use of smart packaging technologies

- Testing programmes using analysis methods that can detect counterfeiting.

- Cyber management protocols and training

- Horizon scan for potential counterfeits and the methods that are being used to produce them. Develop and implement an anti-counterfeiting strategy.

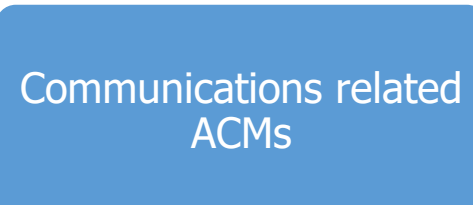

Distribution related ACMs

\section{Price related ACMs}

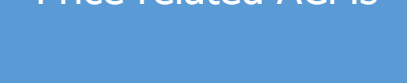

Management system related ACMs 
